\title{
Relationship between Family Meals and Depressive Symptoms in Children
}

\author{
Young-Seok Kim, Min-Ji Lee, Young-Sung Suh, Dae-Hyun Kim*
}

Department of Family Medicine, Keimyung University School of Medicine, Daegu, Korea

Background: Recently, importance of family meals has been emphasized at home and abroad, and several journals reported that family meals had a big impact on children's development. In this paper, we would like to report the relationship between family meals and depressive symptoms in children.

Methods: This study was based on questionnaires distributed to 162 th and 6th graders of one elementary school in the area of Daegu, Korea, in July, 2010. The questionnaire was about general characteristics, family characteristics, and quantity/quality of family meals. Family functions and depressive symptoms in children were evaluated with Smilkstein's family APGAR (adaptability, partnership, growth, affection, and resolve) score (FAS) and Kovac's Children's Depression Inventory (CDI).

Results: In one-way analyses of variance, there was no significant difference in FAS and CDI according to general and family characteristics $(\mathrm{P}>0.05)$. CDI was significantly lower in the group having more frequent family meals $(\mathrm{P}<0.05)$. Higher FAS and lower CDI was seen in the group having more conversation and better atmosphere during meals $(\mathrm{P}<0.05)$. There were no significant differences in FAS and CDI according to the number of participants, duration, and watching television during meals $(\mathrm{P}>0.05)$.

Conclusion: The frequency of family meals, having more conversation and better atmosphere during family meals predicted less depressive symptoms in children.

Keywords: Child; Family Meals; Family Function; Depression

\section{INTRODUCTION}

As socioeconomic environment has changed, children's eating habits have also changed in recent years. According to data from Korea national health and nutrition examination survey

Received: August 31, 2011, Accepted: March 12, 2013

${ }^{*}$ Corresponding Author: Dae-Hyun Kim

Tel: +82-53-250-7548, Fax: +82-53-250-7071

E-mail:dhkim@dsmc.or.kr

Korean Journal of Family Medicine

Copyright (C) 2013 The Korean Academy of Family Medicine

(a) This is an open-access article distributed under the terms of the Creative Commons Attribution Non-Commercial License (http://creativecommons.org/licenses/by-nc/3.0) which permits unrestricted noncommercial use, distribution, and reproduction in any medium, provided the original work is properly cited.
2009, the proportion of children having more than 4 family meals per week was $86.3 \%$ for breakfast, $2.1 \%$ for lunch, and $96.2 \%$ for dinner. ${ }^{1)}$ This is due to the fact that more children are eating out and skipping meals frequently than having meals at home with their family because of the increase in numbers of working parents and growth in private tutors. ${ }^{2)}$

A family meal is when the whole family sits at home around the table and eats together. Through family meals, family members are aware of the concept of community, talk about various family issues, and express the affection and connectedness. ${ }^{3)}$ The frequency of family meals is related to improved quality and balance of diet and eating habits in children. ${ }^{4)}$ In Japan, the negative effects of a lack of family meals or eating alone were already addressed in the 1980s, and it was reported that such effects included children skipping meals and interference with children' s nutrition and eating habits. ${ }^{5)}$ An American study reported that 
family meals decreased the risk of alcohol use, tobacco use, and drug abuse. ${ }^{4)}$ One university also issues annual reports on this and suggests various methods to promote family meals in practical (ways. ${ }^{6}$

Childhood emotional disorders are attributed to various environmental factors including family and school, as well as the biological and psychological factors of children themselves. Among them, family, as a basic unit of society, affects children' s growth, development, and health. ${ }^{7)}$ Social support is mostly obtained from family members and a lack of family intimacy can lead family members to feel depressed and anxious. ${ }^{8)}$ Also, it has been reported that disturbances in family functioning is related to higher risk of depression. ${ }^{9,10)}$

The relationship between the frequency of family meals, life satisfaction, and psychological status was investigated in one domestic study. As a result, the frequency of family meals was related to higher levels of life satisfaction, but it was not related to psychological status including depression symptoms. ${ }^{2)}$ However, since that previous study evaluated individual's depressive symptoms using the 5-point Likert scale, it required further assessment using a tool with better established validity. This study aims to investigate the relationship between family meals and family functioning and depressive symptoms among school age children of one area in Korea.

\section{METHODS}

\section{Participants}

Among 5th and 6th graders of one elementary school in Daegu metropolitan city in Korea, 162 children were surveyed during the day of July 2, 2010. Except 27 questionnaires with insincere or inappropriate responses, 135 (83.3\%) of the final questionnaires were used as the research material.

\section{Measures}

Basic characteristics of the children (grade, sex, height, weight, religion, and illness) and their families (family type, family size, number of siblings, economic level, parent's occupation, and religion) were investigated with self-administered questionnaires. The self-questionnaire included 8 items of quantity and quality of family meals, 5 items of family function index, and 27 items of children's depression inventory.

It was difficult to determine what a family meal means, since the definition varied among studies. ${ }^{1)}$ We defined the family meal as children's eating with at least one parent, and we also rated the number of meals that they had with both parents, with father and with mother, respectively. The survey also included questions on the average number of participants, duration, TV watching, conversations, and atmosphere during meals. The family APGAR (adaptability, partnership, growth, affection, and resolve) score (FAS), which was designed by Smilkstein ${ }^{11)}$ in 1979, was used to measure family function. FAS's validity was established in various studies. ${ }^{12,13)}$ It consists of 5 items including affection, partnership, growth, adaptation, and resolve, and each item is rated from 0 to 2 and the total score ranges from 0 to 10 . A score range in $0-3$ indicates severe family dysfunction, 4-6 indicates moderate dysfunction, and 7-10 indicates healthy family function. ${ }^{12)}$ In this study, however, the total score was evaluated with continuous variables.

The Children's Depression Inventory (CDI), developed by Kovacs in $1983,{ }^{14)}$ was used to assess children's depressive symptoms. This inventory contains 27 self-report items, graded in severity from 0 to 2 and each of the items consists of three statements. The total score ranges from 0 to 54 in which a higher score indicates severe depression. The reliability and validity of the Korean version of this inventory was established. ${ }^{15)}$

\section{Data Analysis}

In order to compare the average score of FAS and CDI according to participant characteristics, family characteristics, and family meals, t-test and one-way analysis of variance was used and the Turkey method was used for multiple-comparison post hoc analysis. A P-value $(\mathrm{P}<0.05)$ was considered significant and data were analyzed using SPSS ver. 12.0 (SPSS Inc., Chicago, IL, USA).

\section{RESULTS}

\section{Description of Study Population and Family Characteristics}

A total of 135 participants consisted of 65 male children (48.5\%), 69 female children (51.5\%), 93 5th graders (68.9\%), 
and 42 th graders $(31.1 \%)$. The number of family members was 4 for 96 participants (71.1\%), and the number of children was 2 for 108 participants $(80.0 \%)$ which were the most. Family type was nuclear family for 128 participants (94.8\%) and single parent for 4 (3.0\%). Self-reported economic status of the family was high for 15 (11.1\%), middle for 69 (51.1\%), and low for 51 (37.8\%).

Table 1. FAS and CDI scores according to general and home environmental characteristics

\begin{tabular}{|c|c|c|c|c|c|c|}
\hline \multicolumn{2}{|c|}{ Characteristic } & \multirow{2}{*}{$\begin{array}{c}\text { Number } \\
93\end{array}$} & \multirow{2}{*}{$\begin{array}{c}\text { FAS } \\
8.0 \pm 1.9\end{array}$} & \multirow{2}{*}{$\frac{\mathrm{P} \text {-value }}{0.75}$} & \multirow{2}{*}{$\frac{\text { CDI }}{9.3 \pm 7.9}$} & \multirow{2}{*}{$\begin{array}{c}\text { P-value } \\
0.93\end{array}$} \\
\hline Grade & 5 & & & & & \\
\hline & 6 & 42 & $7.9 \pm 1.6$ & & $9.1 \pm 9.2$ & \\
\hline \multirow[t]{2}{*}{ Sex } & Male & 65 & $8.0 \pm 2.0$ & 0.93 & $9.5 \pm 8.9$ & 0.75 \\
\hline & Female & 69 & $8.0 \pm 1.7$ & & $9.0 \pm 7.8$ & \\
\hline \multirow[t]{3}{*}{ Family member (person) } & 3 & 16 & $7.6 \pm 1.8$ & 0.70 & $9.8 \pm 5.6$ & 0.41 \\
\hline & 4 & 96 & $8.0 \pm 1.7$ & & $8.6 \pm 7.4$ & \\
\hline & $\geq 5$ & 23 & $7.9 \pm 2.4$ & & $11.7 \pm 12.4$ & \\
\hline \multirow[t]{3}{*}{ Sibling (person) } & 0 & 12 & $7.3 \pm 1.6$ & 0.35 & $9.8 \pm 4.6$ & 0.94 \\
\hline & 1 & 108 & $8.0 \pm 1.8$ & & $9.1 \pm 8.5$ & \\
\hline & $\geq 2$ & 15 & $8.2 \pm 1.9$ & & $9.7 \pm 9.5$ & \\
\hline \multirow[t]{3}{*}{ Economic status } & High & 15 & $9.6 \pm 2.1$ & 0.73 & $9.7 \pm 7.7$ & 0.94 \\
\hline & Middle & 69 & $8.0 \pm 1.7$ & & $9.0 \pm 8.2$ & \\
\hline & Low & 51 & $8.0 \pm 2.0$ & & $9.4 \pm 8.8$ & \\
\hline \multirow[t]{2}{*}{ Religion } & Present & 90 & $7.9 \pm 2.0$ & 0.49 & $9.7 \pm 9.2$ & 0.40 \\
\hline & None & 41 & $8.1 \pm 1.6$ & & $8.4 \pm 6.2$ & \\
\hline \multirow[t]{2}{*}{ Family structure } & Nuclear & 128 & $8.0 \pm 1.7$ & 0.38 & $9.0 \pm 7.5$ & 0.53 \\
\hline & Extended & 6 & $6.7 \pm 3.4$ & & $14.3 \pm 19.4$ & \\
\hline \multirow[t]{2}{*}{ Presence of parents } & Both & 130 & $7.9 \pm 1.8$ & 0.38 & $9.2 \pm 8.3$ & 0.89 \\
\hline & Single & 4 & $8.8 \pm 1.9$ & & $9.8 \pm 9.0$ & \\
\hline \multirow[t]{2}{*}{ Paternal education } & $\leq$ High school & 23 & $7.3 \pm 1.7$ & 0.11 & $9.4 \pm 9.8$ & 0.99 \\
\hline & $\geq$ College & 85 & $8.0 \pm 1.9$ & & $9.3 \pm 8.5$ & \\
\hline \multirow[t]{2}{*}{ Paternal occupation } & Present & 119 & $7.9 \pm 1.9$ & 0.68 & $9.5 \pm 8.6$ & 0.38 \\
\hline & None & 3 & $8.3 \pm 1.1$ & & $5.0 \pm 5.3$ & \\
\hline \multirow[t]{2}{*}{ Paternal religion } & Present & 65 & $7.8 \pm 2.0$ & 0.96 & $9.8 \pm 9.3$ & 0.89 \\
\hline & None & 41 & $7.8 \pm 1.8$ & & $10.1 \pm 7.8$ & \\
\hline \multirow[t]{2}{*}{ Maternal education } & $\leq$ High school & 32 & $7.7 \pm 1.7$ & 0.42 & $8.4 \pm 8.4$ & 0.67 \\
\hline & $\geq$ College & 73 & $8.0 \pm 1.8$ & & $9.1 \pm 7.2$ & \\
\hline \multirow[t]{2}{*}{ Maternal occupation } & Present & 62 & $7.9 \pm 1.7$ & 0.53 & $8.5 \pm 6.0$ & 0.99 \\
\hline & None & 49 & $8.1 \pm 1.8$ & & $8.5 \pm 7.4$ & \\
\hline \multirow[t]{2}{*}{ Maternal religion } & Present & 72 & $7.8 \pm 2.0$ & 0.71 & $10.2 \pm 8.9$ & 0.35 \\
\hline & None & 32 & $7.9 \pm 1.5$ & & $8.6 \pm 6.5$ & \\
\hline Total & & 135 & $8.0 \pm 1.8$ & & $9.2 \pm 8.3$ & \\
\hline
\end{tabular}

Values are presented as mean \pm SD. P-value by t-test or one-way analysis of variance.

FAS: family APGAR (adaptability, partnership, growth, affection, and resolve) score, CDI: children's depression inventory. 
Table 2. FAS and CDI scores according to quantity and quality of family meals

\begin{tabular}{|c|c|c|c|c|c|}
\hline Characteristic & Number & FAS & P-value & CDI & P-value \\
\hline \multicolumn{6}{|c|}{ Meals with both parents (times/wk) } \\
\hline $0-2$ & 37 & $7.4 \pm 2.3$ & 0.130 & $11.7 \pm 10.7$ & 0.177 \\
\hline $3-4$ & 34 & $7.9 \pm 1.6$ & & $9.0 \pm 7.8$ & \\
\hline $5-6$ & 35 & $8.2 \pm 1.5$ & & $8.3 \pm 6.8$ & \\
\hline$\geq 7$ & 29 & $8.4 \pm 1.7$ & & $7.5 \pm 6.5$ & \\
\hline $0-2$ & 37 & $7.4 \pm 2.3$ & 0.07 & $11.7 \pm 10.7$ & $0.04^{*}$ \\
\hline$\geq 3$ & 98 & $8.2 \pm 1.6$ & & $8.3 \pm 7.0$ & \\
\hline \multicolumn{6}{|c|}{ Total family meals (times/wk) } \\
\hline $0-6$ & 23 & $7.61 \pm 1.80$ & 0.723 & $10.0 \pm 6.4$ & 0.430 \\
\hline $7-9$ & 60 & $7.93 \pm 2.01$ & & $9.5 \pm 9.5$ & \\
\hline $10-13$ & 28 & $8.11 \pm 1.66$ & & $10.1 \pm 9.2$ & \\
\hline$\geq 14$ & 24 & $8.17 \pm 1.63$ & & $6.7 \pm 4.7$ & \\
\hline $0-13$ & 111 & $7.0 \pm 1.9$ & 0.54 & $9.8 \pm 8.8$ & $0.02^{*}$ \\
\hline$\geq 14$ & 24 & $8.2 \pm 1.6$ & & $6.7 \pm 4.7$ & \\
\hline \multicolumn{6}{|l|}{ No. of participant } \\
\hline 2 & 17 & $7.1 \pm 2.2$ & 0.14 & $11.1 \pm 5.9$ & 0.77 \\
\hline 3 & 36 & $8.3 \pm 1.6$ & & $9.2 \pm 8.1$ & \\
\hline 4 & 69 & $8.0 \pm 1.8$ & & $8.7 \pm 8.5$ & \\
\hline$\geq 5$ & 13 & $8.1 \pm 2.2$ & & $9.7 \pm 10.8$ & \\
\hline \multicolumn{6}{|l|}{ Required time (min/meal) } \\
\hline$<20$ & 53 & $7.7 \pm 2.1$ & 0.39 & $10.5 \pm 10.0$ & 0.25 \\
\hline $20-40$ & 67 & $8.2 \pm 1.6$ & & $8.0 \pm 6.0$ & \\
\hline$>40$ & 15 & $7.9 \pm 1.9$ & & $9.7 \pm 10.2$ & \\
\hline \multicolumn{6}{|l|}{ Degree of conversation } \\
\hline (1) A little & 17 & $7.1 \pm 2.7$ & $0.03^{*}$ & $16.6 \pm 12.1$ & $<0.001^{\dagger}$ \\
\hline (2) Moderate & 43 & $7.7 \pm 1.6$ & (1) $<$ (3) & $9.1 \pm 7.7$ & (1) $>$ (2), (3) \\
\hline (3) Much & 75 & $8.3 \pm 1.7$ & & $7.6 \pm 6.7$ & \\
\hline \multicolumn{6}{|l|}{ Degree of watching TV } \\
\hline Much & 64 & $8.0 \pm 1.9$ & 0.40 & $9.3 \pm 8.8$ & 0.26 \\
\hline Moderate & 31 & $8.3 \pm 1.6$ & & $7.4 \pm 5.4$ & \\
\hline A little & 39 & $7.7 \pm 2.0$ & & $10.7 \pm 9.2$ & \\
\hline \multicolumn{6}{|l|}{ Atmosphere during meals } \\
\hline (1) Bad & 23 & $6.7 \pm 2.1$ & $<0.001^{\dagger}$ & $16.2 \pm 12.1$ & $<0.001^{\dagger}$ \\
\hline (2) Moderate & 57 & $7.7 \pm 1.6$ & (1), (2) < (3) & $9.0 \pm 7.3$ & (1) $>$ (2), (3) \\
\hline (3) Good & 55 & $8.8 \pm 1.5$ & & $6.6 \pm 5.4$ & \\
\hline Total & 135 & $8.0 \pm 1.8$ & & $9.2 \pm 8.3$ & \\
\hline
\end{tabular}

Values are presented as mean $\pm \mathrm{SD}$.

FAS: family Apgar score, CDI: children's depression inventory.

${ }^{*} \mathrm{P}<0.05 .{ }^{\dagger} \mathrm{P}<0.01$ by $\mathrm{t}$-test or one-way analysis of variance by Turkey's multiple comparison. 
In regards to father's level of education, there were $85(63.0 \%)$ with college graduates or above, 23 (17.0\%) with high school diplomas or below, and 27 (20.0\%) non-responders. In regards to mother's level of education, there were 73 (54.1\%) college graduates or above, $32(23.7 \%)$ with high school diplomas or below, and 30 (22.2\%) non-responders (Table 1 ).

\section{Family Apgar Score and Children's}

Depression Inventory according to Participant Characteristics and Family Characteristics

The overall average score of FAS and CDI was $8.0 \pm 1.8$ and $9.2 \pm 8.3$, respectively, and did not differ according to gender and grade. There was no significant difference in FAS and CDI according to the number of family members, siblings, family type, presence of a parent, and economic status. In regards to father's level of education, FAS was higher and CDI was lower in college graduates or above than in high school or below, however, it was not statistically significant. FAS was low and CDI was high in the non-response group, and similar results were noted according to father's occupation, mother's level of education, and mother's occupation (Table 1).

\section{Family Apgar Score and Children's Depression Inventory according to Family Meals \\ CDI was significantly higher in the group of children who} have meals with both parents less than twice, compared to the group with 3 times or more $(P=0.04)$. CDI was significantly lower in the group of children who have 14 or more meals with at least one parent, compared to the group with 13 or less $(\mathrm{P}=$ 0.02). Low FAS and high CDI was noted in the group with less conversation, and it was statistically significant $(\mathrm{P}=0.03, \mathrm{P}<$ $0.001)$. Better atmosphere during meals was related to higher FAS and lower CDI $(\mathrm{P}<0.001, \mathrm{P}<0.001)$. There was no difference in FAS and CDI according to the number of participants, duration, or TV-watching (Table 2).

\section{DISCUSSION}

Depressive disorder in children has been included in the classification of childhood mental disorders since the Diagnostic and Statistical Manual of Mental Disorders-III $(1980)^{16)}$ and the prevalence ranges from $1.0 \%$ to $8.5 \%$, usually known as $2 \% .{ }^{17)}$ In addition to biological factors such as genetic, neuroendocrine and neurochemical factors and psychological factors are also included in the causes of childhood depression. Family conflict and lack of communication between parents and children is closely related to childhood depression. ${ }^{18)}$ It was reported in one domestic study that disturbed family function is related to childhood depression and anxiety. ${ }^{10)}$ Thus, family function is very important to children's emotional development and this family function can be improved during the time when the family gets together around the table for meals.

It was reported that children eating by themselves showed lower satisfaction with meals and worse nutritional balance than children eating with their family. ${ }^{19)}$ Moreover, children having less frequent family meals were more likely to have negative health symptoms, such as worries, anxiety, fatigue, headache, and dyspepsia. ${ }^{20)}$ In contrast, frequent family meals contributed to prevent juvenile delinquency by increasing life satisfaction and emotional stability, ${ }^{2)}$ and decreasing high-risk behaviors such as sexual behaviors, depression, suicidal attempt, antisocial behaviors, violence, and extreme dieting. Fulkerson et al. ${ }^{21)}$ documented in their study that family meals could significantly (odds ratio, 0.6; 95\% confidence interval, 0.54 to 0.65 ) lower depression and suicidal attempts, however, it was considered a limitation that only one question was asked about each item.

In this study, however, CDI, which was established with validity, was used to assess depressive symptoms, and more questions were asked to assess quantity and quality of family meals. We assessed the number of meals that the children had with both parents, with mother and with father, respectively, as well as the total number of family meals, which was determined as meals with at least one parent. CDI was significantly higher in the group in which children had less than 2 meals with both parents, than in the group of 3 or more. This implies that when the children eat with both parents very rarely, it can affect the children in negative ways but the difference is not big when the frequency is not too low. CID was significantly lower in the group in which children had more than 14 meals with either one of their parents, compared to the group with 13 or less. This suggests that the children who have most meals with their family except lunch have significantly less depressive symptoms than others, however, the difference is not big when the frequency is lower than 13 . 
In addition, the number of the participants in the family meals, duration, the amount of conversation, TV- watching, and the atmosphere were assessed as well in this study, using questionnaires. Among them, the amount of conversation and the atmosphere during meals was associated with FAS and CDI, which implied that the quality of family meals was also very important. It had been reported in other studies that low socioeconomic status ${ }^{22)}$ and a lower level of education for the mother is associated with childhood depression, ${ }^{23)}$ and parents' level of education is related to $\mathrm{CDI},{ }^{10)}$ however, there was no significant difference according to the above items in our study.

The limitations of this study are as follows. First, the casual relationship is unclear between family meals and children's depression. It is not clear if family meals affect family function and children's depression, or, if family function and children's depression affect family meals, or if they both affect each other. Secondly, this study was based on a one-time survey. More reliable data is required from the parents and teachers through direct interviews or by collecting information from them. Lastly, since all the participants were from one certain elementary school and the total number was only 135 , it is difficult to generalize the results of this study to the general population of Korean children.

In conclusion, this study revealed that frequent family meals, better atmosphere, and more conversation during meals was related to decreased depressive symptoms in children.

\section{CONFLICT OF INTEREST}

No potential conflict of interest relevant to this article was reported.

\section{ACKNOWLEDGMENTS}

This study was supported by a grant of the Korean Healthcare technology R\&D Project, Ministry of Health and Welfare, Republic of Korea (A102065).

\section{REFERENCES}

1. Ministry of Health Welfare. Korea health statistics 2009: Korea national health and nutrition examination survey (KNHANES IV-3). Seoul: Ministry of Health Welfare; 2010.

2. Lee YM, Lee KW, Oh YJ. The perceptions and attitudes of elementary school children towards family meals. J Korean Diet Assoc 2009; 15:41-51.

3. Weinstein $M$. The power of family meal which changes the future of the married couple and children (translated version). Seoul: Hans Media; 2006.

4. Eisenberg ME, Olson RE, Neumark-Sztainer D, Story M, Bearinger LH. Correlations between family meals and psychosocial well-being among adolescents. Arch Pediatr Adolesc Med 2004;158:792-6.

5. Adachi M. Theories of nutrition education and promotion in Japan: enactment of the "Food Education Basic Law". Asia Pac J Clin Nutr 2008; 17 Suppl 1:180-4.

6. Joseph A. The importance of family dinners VI. New York: Columbia University; 2010.

7. Rakel RE. Textbook of family medicine. 7 th ed. Philadelphia: Saunders Elsevier; 2007.

8. Cobb S. Presidential Address-1976: social support as a moderator of life stress. Psychosom Med 1976;38:300-14.

9. McNabb R. Family function and depression. J Fam Pract 1983;16:169-70.

10. Park JC, Choi YS, Lee WK, Kim SH, Kim JA, Hong MH. Depression and anxiety trend according to family function in children. J Korean Acad Fam Med 2005;26:536-43.

11. Smilkstein G. The family APGAR: a proposal for a family function test and its use by physicians. J Fam Pract 1978;6: 1231-9.

12. Smilkstein G, Ashworth C, Montano D. Validity and reliability of the family APGAR as a test of family function. J Fam Pract 1982;15:303-11.

13. Yun BB, Kwak KW. The study of family APGAR score as the evaluation method of the family function. J Korean Acad Fam Med 1985;6(12):13-7.

14. Kovacs M; University of Pittsburgh, School of Medicine; Western Psychiatric Institute and Clinic. The children's depression inventory: a self-rated depression scale for schoolaged youngsters. Pittsburgh: University of Pittsburgh; 1983. 
15. Cho SC, Lee YS. Development of the Korean form of the Kovacs' Children's Depression Inventory. J Korean Neuropsychiatr Assoc 1990;29:943-55.

16. American Psychiatric Association. Diagnostic and Statistical Manual of Mental Disorders: DSM-IV-TR. 4th ed. Washington, DC: American Psychiatric Association; 2000.

17. Cho SC. Conception of child psychiatric disorders. Seoul: Seoul National University; 1999.

18. Harrington R. Family-genetic findings in child and adolescent depressive disorders. Int Rev Psychiatry 1996;8:355-68.

19. Sung CJ, Sung MK, Choi MK, Kang YL, Kwon SJ, Kim MH, et al. An ecological study of food and nutrition in elementary school children in Korea. Korean J Community Nutr 2001;6: 150-61.

20. Sung SJ, Kwon S. Effect of eating with family or alone on the self-rated mental or physical health: the elementary school children in Daejeon area. Korean J Community Nutr 2010; 15:206-26.

21. Fulkerson JA, Story M, Mellin A, Leffert N, NeumarkSztainer D, French SA. Family dinner meal frequency and adolescent development: relationships with developmental assets and high-risk behaviors. J Adolesc Health 2006;39:33745.

22. Monroe SM, Bromet EJ, Connell MM, Steiner SC. Social support, life events, and depressive symptoms: a 1-year prospective study. J Consult Clin Psychol 1986;54:424-31.

23. Han E, Yoo AJ. Children's and adolescents' depression, attributional style and academic achivement. J Korean Home Econ Assoc 1994;32:147-57. 